\title{
O CAMINHO SE FAZ CAMINHANDO: HISTÓRIAS DE VIDA E DE APRENDIZAGEM NA CONSTITUIÇÃO PESSOAL E PROFISSIONAL DO(A) EDUCADOR(A) SOCIAL
}

\section{THE WAY FORWARD: LIFE AND LEARNING STORIES IN THE SOCIAL EDUCATOR'S PERSONAL AND PROFESSIONAL FORMATION}

\author{
Juliana dos Santos Rocha \\ Doutora em Educação, Pontifícia Universidade Católica do Rio Grande do Sul - PUCRS \\ Porto Alegre - Rio Grande do Sul - Brasil \\ juliana.rocha.001@acad.pucrs.br \\ Marlene Rozek \\ Doutora em Educação \\ Balneário Camboriú - Santa Catarina - Brasil \\ marlene.rozek@gmail.com
}

Francisco José Del Pozo Serrano

Doutor em Ciências da Educação, Universidad Nacional de Educación a Distancia - UNED

Madri - Espanha

francisd@edu.uned.es

\begin{abstract}
Resumo: Este texto se trata de um recorte com resultados parciais da tese de doutorado em Educação, em andamento, que investiga a constituição subjetiva de educadoras(es) sociais a partir de suas histórias de vida e de aprendizagem. Propõe-se, nesse esforço reflexivo, gerar inteligibilidade sobre: como se constitui o educador social a partir de suas histórias de vida e de aprendizagem? A partir da inspiração na metodologia de História de vida, investigaram-se as trajetórias de um educador social e suas relações com aspectos profissionais e pessoais, buscando compreender como os processos de aprendizagem fazem parte de sua constituição como ensinante e educador social. As bases teóricas da investigação referem-se a: Pedagogia Social, em uma perspectiva crítica; Teoria da Subjetividade; Psicologia Histórico-cultural; e teorias psicopedagógicas. A análise do material empírico foi realizada a partir da Análise Textual Discursiva e os resultados parciais são: a) a relação com os primeiros ensinantes contribuiu significativamente para a constituição do educador, bem como a relação com a religião de matriz africana e o lugar que o saber ocupa em sua cosmovisão; b) as experiências negativas na escola influenciaram os processos de aprendizagem de vida - com família, amigos, educadoras(es) sociais - para que se tornassem centrais na constituição subjetiva do sujeito da pesquisa; c) a relação com a música e o fazer como educador social participam fortemente da sua constituição pessoal, como sujeito que aprende e que ensina.
\end{abstract}

Palavras-chave: aprendizagem; educador social; pedagogia social; subjetividade.

\begin{abstract}
This paper is about a partial cut of the Education doctoral thesis, in progress, that investigates the subjective constitution of social educators from their life stories and learning. In this reflexive effort, is it proposed to generate intelligibility on how social educator is constituted from his life stories and learning? From the inspiration in the methodology of Life History, we investigated the trajectories of a social educator and his relationships with professional and personal aspects, seeking to understand how the learning processes are part of his constitution as a teacher and social educator. The theoretical bases of the investigation refer to: Social Pedagogy, in a critical perspective; Theory of Subjectivity; Historical-cultural Psychology; and psycho pedagogical theories. The analysis of the empirical material was carried out from the Discursive Textual Analysis and the partial results are: a) the relation with his first teachers contributed significantly to the educator's constitution, as well as the relation with the African religion and the place that knowledge occupies in his worldview; b) negative experiences in school influenced his life learning processes - with family, friends, and social educators - to become central in the subjective constitution of him; c) the relationship with music and the role as a social educator had a strong participation in his personal constitution, as a person who learns and teaches.
\end{abstract}

Keywords: learning; social educator; social pedagogy; subjectivity.

Para citar - (ABNT NBR 6023:2018)

ROCHA, Juliana dos Santos; ROZEK, Marlene; SERRANO, Francisco José Del Pozo. O caminho se faz caminhando: histórias de vida e de aprendizagem na constituição pessoal e profissional do(a) educador(a) social. Eccos - Revista Científica, São Paulo, n. 58, p. 1-17, e11572, jul./set. 2021. Disponível em: https://doi.org/10.5585/eccos.n58.11572. 


\section{Introdução}

Nas últimas duas décadas, principalmente a partir da ampliação das políticas de assistência social, os(as) educadores(as) sociais vêm se tornando cada vez mais conhecidos no Brasil. Seu reconhecimento, entretanto, ainda é uma questão que merece atenção (DIAS, 2018), bem como outros aspectos que lhes dizem respeito: condições de trabalho, profissionalização da ocupação, atribuições e formação.

Contudo, investigações que colocam a Pedagogia Social, a Educação Social e os educadoras(es) sociais na pauta científica vêm crescendo e, aos poucos, constroem conhecimento sobre esse campo, o que, por sua vez, permite o desenvolvimento de novas compreensões sobre as mais variadas problemáticas que se apresentam. Nesse sentido, a tese doutoral da qual surge o presente texto tem buscado compreender a constituição subjetiva de educadoras(es) sociais que foram apontadas(os) por adolescentes atendidos em um Serviço de convivência e Fortalecimento de Vínculos da região Sul do Brasil como aquelas(es) com as(os) quais conseguiam aprender e estabelecer um vínculo saudável.

Neste texto, que é um recorte com resultados ainda parciais da tese, buscou-se gerar inteligibilidade sobre: como se constitui o(a) educador(a) social a partir de suas histórias de vida e aprendizagem? São objetivos desse fragmento: a) investigar as trajetórias de um educador social e suas relações com aspectos profissionais e pessoais; e b) compreender como os processos de aprendizagem e as experiências de vida fazem parte de sua constituição como ensinante ${ }^{1}$ e como educador social.

Como base teórica, parte-se do texto intitulado "Lentes teóricas: vislumbrando possibilidades para caminhar", e utiliza-se como principal referencial, no que se refere a Pedagogia Social, Educação Social e educadoras(es) sociais, uma perspectiva mais crítica, tendo como principais autores: Freire (1985), Caride (2005), Úcar (2016b), Del Pozo Serrano (2017) e Ribas Machado (2018). A Teoria da Subjetividade (GONZÁLEZ REY, 1999, 2003; GONZÁLEZ REY; MITJÁNS MARTÍNEZ, 2017) é outro importante marco teórico, pois, a partir dela, busca-se compreender os processos de vida e de aprendizagem de educadoras(es) sociais. Por fim, como base teórica da aprendizagem, utiliza-se a Psicologia Histórico-cultural (GONZÁLEZ REY, 2012; ROCHA; ROZEK, 2017) e a Psicopedagogia (FERNÁNDEZ, 2001; PAÍN, 1996; QUIROGA, 1996), com o intuito de olhar para o aprender como uma produção humana, que ocorre de acordo com as possibilidades de interação dos sujeitos com o mundo.

\footnotetext{
1 Os termos ensinante e aprendente têm valor de conceito para a Psicopedagogia, segundo Fernández (2001). Não é o mesmo que utilizar os termos aluno e professor, que se referem a lugares objetivos em uma relação pedagógica, mas diz respeito a um sujeito que aprende e a um sujeito que ensina, sendo a aprendizagem entendida como processo humano. Ensinante e aprendente são dois espaços simbólicos de um mesmo sujeito.
} 
Trata-se de uma investigação qualitativa, baseada em princípios da Epistemologia Qualitativa (GONZÁLEZ REY; MITJÁNS MARTÍNEZ, 2017; GONZÁLEZ REY; QUEVEDO, 2017), desenvolvida com o objetivo de reflexionar e gerar inteligibilidade acerca de fenômenos subjetivos. A metodologia de trabalho provém de uma inspiração na metodologia de Histórias de vida, nas narrativas autobiográficas (BERTAUX, 2009, 2014; DOMINICÉ, 2006); e, para análise do material empírico, faz-se uso da Análise Textual Discursiva (MORAES; GALIAZZI, 2011). O método desta investigação é detalhado no item 3, "O método: iniciando o percurso".

Sobre os resultados parciais, construídos até essa etapa do processo investigativo, é possível ressaltar que: a) a relação com os primeiros ensinantes contribuiu significativamente pra a constituição do educador, bem como a relação com a religião de matriz africana e o lugar que o saber ocupa em sua cosmovisão; b) as experiências negativas na escola influenciaram os processos de aprendizagem de vida - com família, amigos, educadoras(es) sociais - para que se tornassem centrais na constituição subjetiva do sujeito da pesquisa; c) a relação com a música e o fazer como educador social participam fortemente da sua constituição pessoal, como sujeito que aprende e que ensina, de modo que suas concepções sobre ensinar estão significativamente relacionadas com suas experiências com os primeiros educadores sociais na área da música. Tais resultados são aprofundados no item 4, "Caminhando e fazendo o caminho: análise e discussão do material empírico".

\section{Lentes teóricas: vislumbrando possibilidades para caminhar}

A Pedagogia supõe a condução, a orientação e o acompanhamento das pessoas tendo em vista potencializar suas produções e seus contextos a partir dos processos educativos. Enquanto a Pedagogia escolar centra-se nos aspectos curriculares e didáticos da Educação, a Pedagogia Social (cuja origem é disciplinar para estudar e apoiar o educativo das questões sociais) caracteriza-se, em sua essência, por não ser destinada principalmente ao âmbito escolar, mas não ter um espaço concreto, nem um tempo determinado. Centra-se, assim, nas aprendizagens que se desenvolvem na cotidianidade.

Nesse sentido, Del Pozo Serrano (2017, p. 99, tradução nossa) destaca que 
ainda que as Pedagogias do social tenham diversas trajetórias e tendências a nível universal em seus múltiplos contextos e correntes (europeias, latino-americanas, norte-americanas, asiáticas, etc.), podemos entender a Pedagogia Social como a característica contextualizada do conhecimento científico e da arte que fundamenta e orienta a prática socioeducativa (considerada tradicionalmente para âmbitos não formais ou informais) a fim de prevenir, atuar e reabilitar o indivíduo e/ou a coletividade/comunidade; formar a nível educativo social e sociocultural desde a diversidade, assim como fomentar a promoção, a participação, a potencialização pessoal e comunitária, a ética e a política a partir dos direitos humanos e ambientais para melhorar a qualidade de vida, a justiça e o bem-estar com enfoque crítico e transformador.

É a partir desse marco que se entende a necessidade de formação de educadores sociais que participam de múltiplos processos com as populações-alvo da Educação Social (entendida aqui como campo), em um tempo global de incertezas e complexidades, no qual a ação supõe a contínua e sólida formação técnica (para utilizar ferramentas, metodologias, estratégias, em situações locais e gerais diversas, de múltiplas formas, que mudam constantemente), com enfoque fortemente humanista, com sólidos princípios axiológicos, teóricos e filosóficos que suportem a tomada de decisões de forma crítica.

Esse é o grande desafio da Pedagogia Social: orientar os processos educativos no campo da Educação Social, que apresentam diferenças significativas se se destinam a situações de conflito, risco ou vulnerabilidade (Pedagogia Social especializada) ${ }^{2}$, ou se se destinam a educação e desenvolvimento comunitário e/ou ao trabalho com populações específicas, como mulheres, idosos, etnias, infâncias, adolescências ou juventudes. O que costuma acontecer atualmente é que as intervenções precisam ser pensadas de forma intersetorial com influência da maioria dos âmbitos e tipologias, devido à complexidade.

Nesse sentido,

consideramos imprescindível enfatizar os significados que a dialética objetividadesubjetividade transferem ao fazer pedagógico-social, tanto em seus discursos, como em sua prática, na hora de tomar decisões, de fazer previsões, de estabelecer estratégias, avaliar processos, etc. (CARIDE, 2005, p. 64, tradução nossa).

É essencial, a nível sociopedagógico, que se leve em consideração os significados construídos nos contextos e em situações específicas, de modo a evitar generalizações estabelecidas por leis universais (VÉLEZ DE LA CALLE, 2010), tendo em vista favorecer a horizontalidade da relação e a dialogicidade nos processos de aprendizagem que se constroem nos diferentes espaços (FREIRE, 1985; RIBAS MACHADO, 2018).

\footnotetext{
${ }^{2}$ A Pedagogia Social especializada vem sendo considerada por diversos autores europeus como um campo da Pedagogia Social que intervém em situações, que pela sua complexidade vinculada a violação de direitos e dignidade (risco, conflito; tradicionalmente denominadas situações de inadaptação, exclusão ou ressocialização), exige serviços, programas e recursos especializados.
} 
A partir dessa perspectiva teórico-disciplinar, a Pedagogia Social orienta a ação educativa, no campo da Educação Social, que pretende ser uma ação profissional do educativo e do científico-social para oferecer as bases a educadoras(es) sociais para a atuação profissional, já que elas(es) são atores diretos da relação socioeducativa, na qual as subjetividades são uma dimensão imprescindível para construir vínculos que favoreçam efetivas e significativas ações e aprendizagens (ÚCAR, 2016b). Assim, ainda que haja na cotidianidade do seu exercício, necessitam se manter permanentemente reflexivas(os), investigativas(os) e críticas(os).

Nesse sentido, compreende-se a importância também dos aspectos subjetivos da constituição dessas(es) educadoras(es). Por isso a Teoria da Subjetividade vem sendo a base teórica para pensar, refletir e gerar inteligibilidade pela via da ciência a respeito dessa ocupação. Tal perspectiva rompe com a concepção de subjetividade como dimensão intrapsíquica, com a visão de que o indivíduo internaliza (subjetiva) o objetivo, em um processo linear e causal. Em oposição, contudo, a subjetividade é compreendida como uma qualidade característica da experiência humana, e ocorre no contexto cultural, "na qual a própria subjetividade é condição de seu desenvolvimento e dentro da qual tem sua própria gênese, socialmente institucionalizada e históricamente situada” (GONZÁLEZ REY; MITJÁNS MATÍNEZ, 2017, p. 27).

Desse modo, os processos humanos são essencialmente subjetivos, ao passo que as produções simbólicas são emocionalmente configuradas desde sua própria gênese e as emoções tornam-se, também, simbólicas; trata-se de um complexo sistema simbólico-emocional, que não é linear, nem determinista, nem universal. Nessa perspectiva, a subjetividade se organiza recursivamente em dois planos: individual e social, como duas faces de uma mesma moeda.

Então, a partir das experiências de vida, das trajetórias de aprendizagem, formais e não formais, e das relações afetivas vai se constituindo o(a) educador(a) social, a pessoa, produzindo sentidos e configurações subjetivas, como sistemas abertos, mas com alguma estabilidade, de acordo com as possibilidades de produção subjetiva que foi criando ao longo da vida. Essa produção é dialética - a pessoa produz subjetividade social e é produzida por ela. Entretanto, esse processo não é linear e causal, portanto, investigar as trajetórias individuais contribui significativamente para a compreensão tanto do social quanto do individual.

Nesse ínterim, o aprender também é entendido como essencialmente subjetivo, que ocorre ao longo da vida, não estando estritamente relacionado à escolarização. No processo de humanização o homem sempre aprende, pois precisa aprender para se constituir como tal. Desde o uso da ferramenta mais simples até a criação mais complexa da existência humana, em todos os processos, de diferentes formas e ritmos, com significados e emoções, por necessidade ou por prazer de dominar o instrumento, o homem aprende (ROCHA; DI FRANCO, 2017). Desse 
modo, compreende-se que o aprender é um processo humano, que ocorre desde a mais tenra idade até a morte.

Tem-se a concepção, então, de que o homem se tornará homem ao longo de sua vida a partir do contato com outros homens, conforme se insere em uma cultura, dotada de história, em uma família, com compreensões de mundo e de vida específicas. Desse modo, considera-se que os primeiros cuidadores têm papel essencial no desenvolvimento biológico, social e psicológico. É nesse contexto primário de socialização que o indivíduo tem as primeiras possibilidades de aprender sobre o mundo no qual está inserido. Assim, constitui-se em uma práxis, em um fazer, em uma relação ativa com o real no qual se modifica e modifica o mundo (QUIROGA, 1996).

É possível, então, entender a complexidade dos processos de aprendizagem, que não são um simples processamento de informações, mas compreensão e atribuição de significados. Mais do que pensar, é necessário refletir sobre o que se pensa e, assim, compreender como ocorre a produção de significados ensinados e transmitidos cotidianamente. Além dos significados, parte da subjetividade social, o aprender se dá ainda na complexidade da subjetividade individual do sujeito. Portanto, no movimento dialético entre social e individual, no qual o sujeito produz sentidos subjetivos que se relacionam às aprendizagens, aos ensinantes, às vivências nas quais aprendeu, tornando o processo de aprendizagem ainda mais complexo (GONZÁLEZ REY, 2012).

\section{0 método: iniciando o percurso}

Esta investigação, de cunho qualitativo, vem sendo desenvolvida inspirada em princípios da Epistemologia Qualitativa (GONZÁLEZ REY; MITJANS MARTÍNEZ, 2017), pois trata-se de uma concepção em que as teorias não são tidas como dogmas, mas como sistemas de base para as construções teóricas das pesquisas e das práticas pertinentes ao próprio desenvolvimento do homem e do sistema no qual se faz (GONZÁLEZ REY, 2012). É, pois, uma perspectiva que vem tratando de superar as tradições rígidas, instrumentais e quantitativas da ciência - que dicotomizam o sujeito e supervalorizam suas práticas, como se elas não estivessem intimamente atreladas ao indivíduo que as realiza, entendendo que somente a partir de um paradigma mais complexo, e menos rígido, é possível investigar os fenômenos subjetivos.

González Rey (2005) ressalta que, para a Epistemologia Qualitativa, a construção do conhecimento fundamenta-se, especialmente, em três princípios: 1) seu caráter construtivo 
interpretativo, o que implica compreendê-lo como produção permanente, não como uma apropriação linear de algo pronto; 2) a legitimação do singular é fonte de conhecimento - a pesquisa é considerada produção teórica no que tange à construção interpretativa do pesquisador a partir do arcabouço teórico com o qual realiza tais construções; e 3) a pesquisa nas ciências antropossociais precisa ser entendida como um processo de comunicação e diálogo, visto que grande parte dos problemas sociais e humanos emerge, direta ou indiretamente, da comunicação entre as pessoas. Nesse sentido, a comunicação se torna um espaço privilegiado para a investigação.

Elegeu-se as Histórias de vida com o intuito de estabelecer um diálogo que permitisse perceber a ação e o pensamento do sujeito que narra, o qual expressa emoções e que se conta a partir do hoje, acessando diferentes emocionalidades a partir da narrativa e do diálogo, com o (re)viver das experiências que relata. De acordo com Bertaux (2014), não há ninguém que possa contar melhor a história do que aquela pessoa que a viveu, ainda que a modifique por diferentes motivos, "o resultado será bastante mais rico em informação factual e em percepção sobre os significados subjetivos que qualquer questionário ou uma hipotética, mas impossível, observação direta” (BERTAUX, 2014, p. 261).

Assim, o presente texto parte da análise do material construído em três encontros com um educador social, o qual utiliza como ferramenta educativa a percussão para desenvolver seu trabalho com crianças e adolescentes no Serviço de Convivência e Fortalecimento de Vínculos, bem como em outros projetos sociais que não estão diretamente vinculados a esse serviço. $\mathrm{O}$ participante tem 29 anos e trabalha como educador social desde os 14 anos. É, também, musicista e trabalha com teatro. Sua inserção na Educação Social não se deu como educador, mas como educando: aos 10 anos começou a frequentar um projeto social de percussão em sua comunidade. Para se referir a ele, será utilizado o nome fictício "Sitar", instrumento indiano citado pelo participante em sua história. Sitar faz parte desta investigação, pois, em um estudo de mestrado, foi citado por adolescentes como um educador social com o qual podiam estabelecer uma relação de parceria para a aprendizagem.

Entende-se, assim, que o exercício de se narrar permite que o indivíduo reflita sobre seus processos, tornando-se, de fato, sujeito de sua produção subjetiva, o que se intensifica com o estabelecimento de um diálogo, na perspectiva de dinâmicas conversacionais, permitindo que o pesquisador retome pontos da narrativa com o indivíduo. Ademais, de acordo com Dominicé (2006), a Educação é feita de momentos, de experiências, que só têm sentido na história de cada sujeito. Desse modo, compreender e interpretar aspectos relacionados a essa esfera da vida do sujeito requerem mais do que meros recortes temáticos, é preciso compreendê-los dentro de 
uma história contada pelo próprio sujeito e que, portanto, já vem carregada de significados e sentidos subjetivos produzidos em relação aos fenômenos.

Para Bertaux (2009), não é necessário que o participante conte sua história completa, do início ao fim, para que se possa chamá-la de história de vida. Ressalta-se que, nesse fragmento, não se realizou uma construção linear da história do participante, mas ele ficou à vontade para apontar os elementos que considerava mais significativos e, a partir de sua narrativa, a pesquisadora foi provocando e retomando questões pertinentes ao problema investigado.

Os encontros foram gravados, mediante o consentimento do participante, transcritos e analisados. O processo de análise foi realizado de maneira concomitante aos encontros, de modo que os pesquisadores foram construindo linhas interpretativas e explorando-as nos encontros, de acordo com as construções e narrativas do participante. Os princípios éticos foram totalmente respeitados e estão de acordo com a Resolução n ${ }^{\circ} 510$ de 2016, de modo que os pesquisadores tiveram assentimento do participante, se dispuseram a prestar assistência se necessário e mantiveram sigilo em relação à sua identificação.

Para a análise feita neste trabalho, utilizou-se a Análise Textual Discursiva (MORAES; GALIAZZI, 2011), a qual pressupõe uma análise exaustiva e criteriosa do material empírico e é composta por três fases: unitarização, categorização e construção de metatextos.

A primeira fase se refere a leitura, fragmentação e desconstrução do texto, a partir das quais os pesquisadores o separam por unidades de sentido e depois reescrevem as frases de modo que tenham sentido em si mesmas. Na segunda fase, essas unidades de sentido são progressivamente agrupadas, com o intuito de construir categorias de sentido. Nesse processo, as unidades de sentido são agrupadas e reagrupadas quantas vezes forem necessárias para que os pesquisadores construam categorias finais que permitam gerar inteligibilidade sobre o problema proposto. Por fim, os pesquisadores constroem textos interpretativos acerca dessas categorias, no qual fazem o trabalho artesanal da pesquisa científica: a costura entre o empírico e o teórico, sistematizando novas compreensões sobre o tema.

$\mathrm{Na}$ análise do material foram construídas e reescritas 624 unidades de sentido. Em um primeiro momento de categorização, surgiram 21 categorias que, posteriormente, foram reorganizadas e se tornaram 6 categorias, resultando em 3 categorias finais: família, escola e música/arte. Tais categorias serão discutidas e analisadas a seguir, de modo que será possível encontrar as subcategorias que as compõem, bem como as linhas analítico-interpretativas construídas pelos autores. 


\section{Caminhando e fazendo o caminho: análise e discussão do material empírico}

Conforme citado anteriormente, Sitar tem 29 anos, é educador social, musicista e compositor. Tem, ao todo, 14 irmãos. É de família pobre, da periferia, de uma cidade da região metropolitana de Porto Alegre. Filho de pai motorista de ônibus e mãe faxineira e cuidadora. De religião de matriz africana, na casa de sua mãe há um terreiro, assim, a religião sempre foi significativa em sua vida, consequentemente a música e o som também. A narrativa de Sitar é muito semelhante às de seus educandos(as), os(as) quais o indicaram como um educador com o qual eles(as) conseguiam estabelecer um vínculo importante para a aprendizagem.

$\mathrm{Na}$ análise do material transcrito a partir das entrevistas com Sitar, chegou-se a três categorias finais: família, escola e música/arte. Na primeira categoria - família -, encontramse as subcategorias: religião, ludicidade, aprendizagem e relações familiares; na segunda categoria - escola -, encontram-se: racismo, hierarquias, aprendizagem, significado do professor; e, na terceira e última categoria, encontram-se as seguintes subcategorias: relação com a arte, curiosidade e criatividade, aprendizagem, emancipação, encantamento, relações afetivas e sensibilidade.

É importante salientar que, embora estejam separadas para fins de análise, as categorias se entrelaçam, pois entende-se que a subjetividade da pessoa ocorre em um processo dinâmico e recursivo, que apesar de se organizar em configurações, se conectam entre si. Aprendizagem, por exemplo, um dos principais conceitos para esta investigação, aparece nas três categorias finais, o que permite construir uma linha de interpretação que atribui diferentes significados e sentidos às experiências de aprendizagem do participante.

Já no início de sua narrativa, Sitar diz: “agora, observando já com certo grau de maturidade, acho que esse negócio de ser educador social vem de muito antes” e, em seguida, começa a narrar suas histórias na família. Sitar conta com detalhes algumas vivências com a mãe, uma pessoa bastante significativa em sua constituição aprendente. Foi na relação com a mãe e com uma das irmãs mais velhas que ele aprendeu a gostar de ouvir histórias, muitas delas sobre seus ancestrais e sobre a religião de matriz africana. É nessa relação que Sitar fala sobre a magia, a ludicidade e a relação afetuosa que tinha com suas primeiras ensinantes significativas e é também dessa relação que nasceu o gosto pela aprendizagem e por ensinar, o que pode ser observado na narrativa a seguir:

Esse negócio de brincar de escolinha, essas coisas assim, sabe? Esse sempre foi um
tipo de brincadeira que eu sempre me dava muito bem porque... muito observando
minha mãe, ela tem uma maneira de transmitir conhecimento que é encantador [...].
Ela tem uma facilidade de explicar, de falar fácil, sabe? Então, ela transmitia algumas
coisas, principalmente contando histórias, esse negócio de contar história, de levar a
gente para o imaginário [...]. (Sitar) 
As primeiras situações de aprendizagem e também a ocupação desse espaço simbólico de ensinante, de acordo com Sitar, foram nesse ambiente seguro e construído na base do afeto, a família. De acordo com Quiroga (1996), o sujeito vai construindo matrizes de aprendizagem (formas de aprender e de se aproximar do conhecimento) desde as suas primeiras relações, com os seus primeiros ensinantes. Essas matrizes não são fixas e imutáveis, mas têm certa estabilidade, conforme vão sendo construídas ao longo da vida, de acordo com a relação do sujeito com o real, nas suas experiências de vida e formação. Nesse sentido, entende-se que as primeiras experiências de Sitar na família foram significativas para o que ele se tornou.

A relação de Sitar com a música também é precoce. Inicialmente ele conta que ingressou em um projeto social de música aos 10 anos, contudo, posteriormente lembra que sua relação com a música aconteceu muito antes, no terreiro, na religião de matriz africana. Ele tocava tambor desde muito pequeno e conta que sempre foi fascinado pelo som, mas foi ao ingressar no projeto social que se intensificou o gosto por aprender, a curiosidade e suas experiências como ensinante. Nesse sentido, Sitar conta:

\begin{abstract}
Quando começou a minha história com música, com arte em específico, eu chegava em casa, e voltava e queria ensinar para a minha mãe o que eu tinha aprendido, então era... Nossa! Era o momento de troca. Eu ensinava para ela o que eu tinha aprendido na aula de música e ao mesmo tempo que eu tinha uma facilidade, um gosto por aprender, eu tinha um gosto por transmitir o que eu tinha aprendido também, né! Era quase como se fosse uma brincadeira e a regra dessa brincadeira é: "tu só vai mostrar que tu aprendeu se tu conseguir ensinar".
\end{abstract}

É possível perceber, então, que em suas experiências familiares Sitar também teve vivências positivas relacionadas a ensinar. Aprender e ensinar no ambiente familiar se configuraram subjetivamente para ele como brincadeira, afeto, amor. Em outro momento, ele refere que "então, aprender não era... aprender em casa não era uma coisa, um calvário, porque na escola sempre foi uma coisa muito triste para mim assim, mas aprender em casa...". Aprender em casa era suficientemente bom para que ele tenha persistido no caminho. Ou seja, ainda que tenha encontrado barreiras significativas nos processos de aprendizagens formais, Sitar produziu o que parece ser uma emocionalidade positiva em relação ao aprender e ao ensinar.

A religião, como uma subcategoria da família, tem significativa importância na história de vida e na aprendizagem do sujeito. Sitar refere que na religião de matriz africana "o saber ocupa um lugar diferente"; referia-se a forma como se transmite o saber, oralmente, como algo que é precioso. Ou seja, nessa cosmovisão, transmitir os saberes às seguintes gerações é essencial para a continuidade da cultura e a sobrevivência do povo. De acordo com Sitar, é diferente da cultura ocidental, na qual a detenção do saber garante poder e dominação. Portanto, 
aprender e ensinar são configurados subjetivamente como tradição, cuidado com o outro e cultura.

A segunda categoria - escola - não aparece na história de vida de Sitar, em primeira análise, como algo positivo. Contudo, sua produção subjetiva em relação à escola pôde ser transformada em motivação para a escolha de ser educador social. Sitar fala sobre a escola como um espaço bastante negativo, no qual sofreu, desde o início, racismo:

\footnotetext{
Por exemplo, na escola eu tive, e hoje eu falo isso porque acho que é uma maneira de militância, mexer nessas coisas que são tristes para a gente, principalmente da infância... Eu sofri racismo por uma professora, que disse que eu não aprendi porque eu era um preto burro e aí quando ela coloca isso, quando uma pessoa que é uma pessoa que está ali para cuidar de ti, os professores estão para cuidar da gente, né! E cuidar não no sentido, não só sendo pragmático né, cuidar no sentido muito mais amplo. Tu tá formando, tá formando um ser [...]. (Sitar)
}

Na continuidade dessa narrativa, ele diz que chegou em casa e contou para sua mãe, que foi até a escola tirar satisfações. Segundo ele, nesse momento ele aprendeu algo, ainda que não soubesse na época o que era, aprendeu a "não levar desaforo para casa". De fato, essa parece ter sido uma aprendizagem bastante significativa: Sitar hoje usa a música como ferramenta para sua militância e compõe letras que falam sobre os povos originários da África, ancestralidade, religião de matriz africana, genocídio da juventude negra, racismo. Ele diz: "aí quando eu comecei a dialogar com a música foi como se eu encontrasse... encontrasse a arma certa!".

Apesar disso, quando Sitar fala sobre as aprendizagens escolares, sua emocionalidade expressa as dificuldades encontradas no percurso de escolarização. As marcas deixadas pela escola são importantes para sua trajetória, mas isso não significa que ele as sinta como experiências positivas. Os sentidos subjetivos produzidos em relação à figura do professor contribuem para que Sitar considere a importância da figura do educador, ou de educadores(as), em sua trajetória. Ao falar sobre a figura do professor, ele diz: “depois disso, para mim professor era aquilo, era alguém que te colocava para baixo, era alguém que ia te... Que ia pegar a tua condição física, tua condição de fenótipo e ia colocar aquilo primeiro e antes de tudo".

Ao falar sobre o quanto as(os) professoras(es) foram racistas, o quanto atuavam na lógica da exclusão de qualquer diferença, Sitar cita também sobre como percebeu, com o tempo, que essa lógica excludente é da instituição escolar e sobre como as(os) professoras(es) reproduzem essa lógica; uma lógica que gera privilégios e mantém o status quo (ARIÈS, 1981).

Outro aspecto que aparece de forma significativa na narrativa de Sitar é a questão da hierarquia existente na escola, o que se articula com as questões supracitadas nessa categoria. Para ele, a relação desigual de poder entre professoras(es) e alunas(os) dificulta os processos de aprendizagem, pois, pela sua própria experiência, relacionar-se nesses termos foi bastante 
difícil. Quando relaciona esse tópico à sua experiência profissional refere: "prefiro que me chamem pelo nome".

A relação de parceria citada pelos educandos e educandas de Sitar, quando se referem a ele como alguém com quem podem contar, aparece em sua história de vida como dois extremos: quando se refere aos professores da escola, ele fala sobre os aspectos negativos que experienciou na relação de poder; e, quando fala de educadoras(es) sociais que foram importantes em sua vida, refere-se à importância dessas relações e sobre ter tido as mais diversas aprendizagens com essas pessoas, de forma muito similar ao que aparece nas histórias de vida das(os) educandas(os). Ou seja, as relações que se estabelecem na história de vida de Sitar em contextos não escolares permitiram que ele estabelecesse uma relação saudável com a aprendizagem, ainda que as aprendizagens escolares tenham sido negativas, pois os sistemas nos quais o sujeito interage participam continuamente de sua produção de subjetividade (SCOZ; TACCA; CASTANHO, 2012).

Sitar conta sobre o seu ingresso no projeto social e sobre como foi intensa sua relação com a música e com a aprendizagem dela:

\footnotetext{
Eu me lembro em específico da primeira aula de música... Teve um educador [...]. Ele chegou, ele era um menino também, deveria ter uns 20 e poucos anos e eu era uma criança, né! E ele chegou para dar aula de música e ele fez percussão corporal, ele tirava o som do corpo. [...] Era umas coisas muito de brincadeira com criança, tirar som com a cavidade da face, som da palma, esse tipo de coisa... Só que para mim aquilo era muito legal, eu falei: "Nossa! Isso aqui é o suprassumo", do tipo, era algo que eu nunca tinha visto, aí eu fui para casa me estapeando, né, para aprender a tirar som [...]. (Sitar)
}

Na sequência, Sitar conta que a partir dessa primeira experiência passou a se interessar cada vez mais pela música, tirava som de tudo e passou a estudar usando as revistas sobre música que havia no projeto. Descobriu um mundo novo, com estilos musicais, instrumentos e musicistas que não conhecia, e nesse momento de descoberta cita o instrumento indiano "Sitar". Levava as revistas emprestadas, algumas tinham CDs, o que o permitia escutar muita coisa.

Nesse processo, ele cita que foi mostrar ao educador que havia observado o que ele fazia e que já sabia fazer vários sons, pois havia aprendido. Tal qual fazia com a mãe, mostrar o que havia aprendido, fez com o educador e relata que a reação dele foi de felicidade. Nesse momento, refere sobre o quão bom é ver que um educando aprendeu, um sentimento que está ao mesmo tempo relacionado à sua vivência como filho, como educando e como educador: “porque o demonstrar no fazer é uma demonstração de afeto também, né!”. O afeto e o vínculo aparecem com muita frequência em sua narrativa e em lugar de destaque, remetendo-se constantemente àquelas(es) que lhe ensinaram. 
Outra questão importante relacionada às experiências com a música é a ideia de protagonismo, de autoria, que Sitar relata ter tido com a música e que é bastante significativo para sua constituição como educador, para a forma como se posiciona hoje diante das(os) educandas(os). Ele narra:

naquele universo [da música] tu era o grande protagonista, era um outro negócio né, quando é que... no aprendizado tu nunca é o protagonista né, na escola. A escola não te coloca nesse lugar, como um sujeito responsável pela sua história, sabe? [...] E nesse universo da música eu era o meu sujeito, eu podia fazer o que eu queria, eu tinha 20 braços, eu tinha 20 cabeças, podia pensar várias coisas diferentes, sabe?

Para Úcar (2016b), autonomia, empoderamento e consciência são desafios que estão na centralidade do fazer na Educação e na Pedagogia Social, de modo que as(os) educandas(os) tenham consciência sobre si e sobre o mundo e, por elas(es) mesmas(os), resolvam qual o seu "que fazer" no mundo. Nesse sentido, Sitar teve uma importante experiência na vida: pôde, a partir de uma relação importante com um educador, de suas produções subjetivas desde a primeira infância, começar a construir recursos, a partir da música, para sua ação no mundo.

É, pois, a um educador que ele atribui um dos momentos importantes de sua trajetória:

Eu acho que um que foi uma divisão assim enquanto válvula motriz. [...] E ele tinha uma coisa de cativar os educandos assim no bom humor, pela alegria e pela capacidade que ele tinha de achar alguma coisa de bom em todo mundo e tentar ficar com aquilo e fazer com que a pessoa visse que ela tinha aquilo também.

Sitar relata que a partir dessa relação, do olhar cuidadoso do educador para suas potencialidades, ele descobriu que existiam muitas possibilidades. Refere-se, então, a uma relação de confiança. E, ao narrar outro momento significativo de sua história, conta sobre a ligação que recebeu de um ex-educando quando o irmão mais novo dele foi preso, dizendo que não sabia a quem recorrer e que as pessoas o julgariam. Sitar, emocionado, fala sobre os vínculos construídos, baseados na confiança mútua e no respeito. Relações que são construídas desde o seu lugar de educando, com educadores nos quais ele podia confiar e que nele depositaram confiança.

Para Outeiral e Cerezar (2011), a atualidade exige um(a) educador(a) que suporte a demanda emocional das(os) educandas(os). Que seja autoridade sem ser autoritário, criando um espaço seguro no qual se compreenda a importância dos limites, sobretudo no qual o limite seja entendido como amor, como cuidado. Trata-se de uma demanda importante na contemporaneidade, em que as verdades, os valores e a ética são relativizados e sofre-se, como humanidade, uma crise. 
A respeito da consciência, é possível destacar, ainda, o quanto Sitar conhece sua história, a história de seus ancestrais, o quanto sabe sobre política, bem como é engajado nas lutas do povo negro, o quanto estuda e lê, ainda que não tenha concluído o curso superior de licenciatura em música que iniciou. Entende-se que essa consciência acerca do seu lugar no mundo tem uma relação significativa com o seu modo de ser educador, com as relações vinculares que estabelece com seus educandos. Para Úcar (2016a), essa consciência de si permite que a pessoa saiba do seu potencial, mas também dos seus limites, da sua finitude e incompletude, o que é essencial ser desenvolvido no trabalho sociopedagógico.

Destaca-se, por fim, que possivelmente as concepções de Sitar sobre aprendizagem, construídas a partir dessas trajetórias, tenham importante relação com o educador que é hoje. Falando sobre o aprender, ele diz: "ouvindo e conversando com o outro a gente aprende muita coisa, e aprende num grau muito além, por que tu tá aqui, tu pode tocar na pessoa, tu pode cheirar ela, tu pode ouvir a voz dela, tu pode ver a cor dela, o cabelo [...]”.

Essa é, pois, uma concepção bem mais ampliada e complexa a respeito dos processos de aprendizagem, o que permite que Sitar pense no ensinar, também, como um processo mais complexo. De acordo com Paín (1999), a aprendizagem é um processo complexo, composto por quatro instâncias: organismo, inteligência, corpo e desejo. Nessas instâncias estão aspectos orgânicos, corporais, subjetivos, sociais e cognitivos engendrados em uma trama complexa que se constitui ao longo da vida. Quando um ensinante, de alguma forma, ainda que não tenha uma concepção teórica demarcada, consegue perceber a complexidade do processo e coloca-se em uma relação horizontal na construção do conhecimento com o outro, esses processos tendem a ser muito mais prazerosos.

Constituir-se como educador social é, sem dúvida, um processo de vida. O que aqui não significa de forma alguma que não haja necessidade de formação de educadoras(es) sociais, porém, estas formações precisam estar embasadas em pressupostos que considerem os processos de vida, as histórias, os contextos, desse profissional. Para Sitar, esse processo, sempre em construção, passa pela história da família, pelas suas experiências na escola, pela sua aproximação com a música e com outras formas de arte, pela sua vivência da religião, pela sua militância, pelos vínculos com ensinantes em diferentes espaços e tempos e pela sua experiência como educador, que iniciou precocemente. Suas aprendizagens no campo, as trocas com os colegas, as aprendizagens com as(os) educandas(os), tudo isso faz parte de uma trajetória única e individual, que se constituiu também na subjetividade social, a partir dos significados construídos e das mais variadas situações. Como desafio, tem-se na área a seguinte 
pergunta: como proporcionar uma formação que contemple os aspectos subjetivos de educadoras(es) sociais? Tema para outra caminhada...

\section{Considerações finais}

Tratando-se de um texto com análises de uma investigação ainda em andamento, salienta-se que essas considerações, ainda que tratem de encaminhar o texto para o final, são parciais, haja vista a complexidade da temática abordada e a continuidade da investigação. Contudo, é possível inferir que, a partir do problema proposto - como se constitui o educador social a partir de suas histórias de vida e de aprendizagem? -, na história de vida do participante em questão, destacam-se três componentes importantes: a família, a escola e a música.

Esses três componentes se entrelaçam ao longo das histórias narradas e o constituem tanto como aprendente quanto como educador. Entende-se que suas relações familiares, principalmente com a mãe, são constituintes desses dois espaços simbólicos (aprendente e ensinante). Foi no cotidiano, ao brincar de escolinha, ao ouvir histórias e ao ensinar o que havia aprendido, que Sitar teve suas primeiras e mais significativas vivências desses papéis. O aprender e o ensinar, em um ambiente de amor e cuidado, possivelmente permitiram a ele produzir uma subjetividade que se expressa pelo cuidado com seus educandos.

As configurações subjetivas de Sitar sobre o aprender na vida - em casa, com a música, no trabalho, como educando em projetos sociais -, são expressas por criatividade, curiosidade, vontade de aprender, prazer, diferentemente das configurações subjetivas do aprender na escola, que estão muito relacionadas à experiência negativa que ele teve na instituição escolar, na qual o racismo e a exclusão apareceram como elementos bastante marcantes em sua vida. Entretanto, acredita-se que a experiência ruim com a escola contribuiu para que a relação com outras aprendizagens fosse mais significativa, haja vista que muitas vezes, ao narrar sua história, ele compara os dois ambientes de aprendizagem e destaca as possibilidades de aprender do espaço da Educação Social, dando destacado lugar para o primeiro, de educador de música. Ainda que a subjetividade seja produzida individual e socialmente, essa produção não é linear e causal.

A reflexão de Sitar sobre seus processos de ser e estar no mundo, seu conhecimento sobre sua história e a história do povo negro no Brasil, a consciência de classe, o engajamento ético e político, fazem parte de uma construção individual e coletiva, mas essencialmente subjetiva. Seu engajamento subjetivo com a profissão de educador social certamente tem relação com sua história de vida, com o menino negro e de periferia que sofreu racismo e que encontrou no campo social a inspiração para a luta, encontrou seu lugar no mundo. 


\section{Referências}

ARIÈS, Philippe. História social da criança e da família. Rio de Janeiro: LTC, 1981.

BERTAUX, Daniel. A vingança do curso de ação contra a ilusão científica. Civitas, Porto Alegre, v. 14, n. 2, p. 250-271, mai./ago. 2014. Disponível em http://revistaseletronicas.pucrs.br/ojs/index.php/civitas/article/download/17147/11472. Acesso em: 2 set. 2021.

BERTAUX, Daniel. Le récit de vie. Paris: Nathan, 2009.

CARIDE, José Antonio. Las fronteras de la pedagogía social: perspectivas científica e histórica. Barcelona: Gedisa, 2005.

DEL POZO SERRANO, Francisco. Pedagogía Social en Colombia: entre la experiencia de la educación popular y el reto de la investigación-acción en la profesionalización socioeducativa de un país en posconflicto. Ensino \& Pesquisa, v. 15, n. 2, p. 97-116, jul. 2017. Disponível em: http://periodicos.unespar.edu.br/index.php/ensinoepesquisa/article/view/1644. Acesso em: 2 set. 2021.

DIAS, Santiago P. Educadoras e educadores sociais de Porto Alegre em busca de reconhecimento. 2018. 262 f. Dissertação (Mestrado em Ciências Sociais) - Programa de Pósgraduação em Ciências Sociais, Pontifícia Universidade Católica do Rio Grande do Sul, Porto Alegre, 2018.

DOMINICÉ, Pierre. A formação de adultos confrontada pelo imperativo biográfico. Educação e Pesquisa, São Paulo, v. 32, n. 2, p. 345-357, mai./ago. 2006. Disponível em: http://www.revistas.usp.br/ep/article/view/28014. Acesso em: 2 set. 2021.

FERNÁNDEZ, Alícia. Os idiomas do aprendente: análise das modalidades ensinantes com famílias, escolas e meios de comunicação. Porto Alegre: Artmed, 2001.

FREIRE, Paulo. Pedagogía del oprimido. Montevideo: Tierra Nueva, 1985.

GONZÁLEZ REY, Fernando. A configuração subjetiva dos processos psíquicos: avançando na compreensão da aprendizagem como produção subjetiva. In: MITJÁNS MARTINEZ, A.; SCOZ, B. J. L.; CASTANHO, M. I. S. (Orgs.). Ensino e aprendizagem: a subjetividade em foco. Brasília: Liber Livro, 2012. p. 21-42.

GONZÁLEZ REY, Fernando. O valor heurístico da subjetividade na investigação em psicologia. In: GONZÁLEZ REY, F. Subjetividade, complexidade e pesquisa em psicologia. São Paulo: Thompson Learning, 2005. p. 27-51.

GONZÁLEZ REY, Fernando. Subjetividad, sujeto y construcción del conocimiento: el aprendizaje desde otra optica. Linhas Críticas, Brasília, v. 4, n. 7-8, p. 17-22, jul. 1998/jun. 1999.

GONZÁLEZ REY, Fernando. Sujeito e subjetividade: uma aproximação histórico-cultural. São Paulo: Thomson Learning, 2003. 
GONZÁLEZ REY, Fernando; MITJÁNS MARTÍNEZ, Albertina. Subjetividade: teoria, epistemologia e método. Campinas: Alínea, 2017.

GONZÁLEZ REY, Fernando; QUEVEDO, Jorge Moncayo. Subjetividad, cultura e investigación cualitativa: los antecedentes desde la personalidad y el método clínico. Bogotá: Editorial Aula de Humanidades, 2017.

MORAES, Roque; GALIAZZI, Maria do Carmo. Análise textual discursiva. Ijuí: Editora Unijuí, 2011.

OUTEIRAL, José O.; CEREZER, Cleon S. Autoridade e mal-estar do educador. São Paulo: Zagodoni, 2011.

PAÍN, Sara. A função da ignorância. Porto Alegre: Artes Médicas, 1999.

PAÍN, Sara. Subjetividade e objetividade: relação entre desejo e conhecimento. São Paulo: CEVEC, 1996.

QUIROGA, Ana. Matrices de aprendizaje: constitución del sujeto en el proceso de conocimiento. Argentina: Editorial CINCO, 1996.

RIBAS MACHADO, Érico. Interfaces entre la educación popular de Paulo Freire y la Pedagogía Social en el contexto brasileño. In: DEL POZO SERRANO, F. J. Pedagogía Social en Iberoamérica: fundamentos, ámbitos y retos para la acción socioeducativa. Barranquilla: Universidad del Norte, 2018. p. 53-71.

ROCHA, Juliana dos Santos; DI FRANCO, Alice. A aprendizagem em contextos de vulnerabilidade social. In: ROZEK, M.; DOMINGUES, C. L. K. As dificuldades de aprendizagem e o processo de escolarização. Porto Alegre: EDIPUCRS, 2017. p. 165-194.

ROCHA, Juliana dos Santos; ROZEK, Marlene. Quando aprender na escola é (im)possibilidade. RLCSNJ, Manizales, v. 16, n. 1, 2017, p. 361-373.

SCOZ, Beatriz; TACCA, Maria Carmen; CASTANHO, Marisa Irene. Subjetividade, ensino e aprendizagem: contribuições de pesquisas acadêmicas. In: MARTINEZ, A. M. SCOZ, B. J. L.; CASTANHO, M. I. S. (Orgs.). Ensino e aprendizagem: a subjetividade em foco. Brasília: Liber Livros, 2012. p. 131-156.

ÚCAR, Xavier. Pedagogía de la elección. Barcelona: UOC, 2016a.

ÚCAR, Xavier. Relaciones socioeducativas: la acción de los profesionales. Barcelona: UOC, 2016b.

VÉLEZ DE LA CALLE, Claudia. Pedagogía Social en Colômbia. Cali: Bonaventuriana, 2010. 